\section{CD14, lösliches}

H. Renz ${ }^{1}$ und B. Gierten ${ }^{2}$

${ }^{1}$ Institute of Laboratory Medicine and Pathobiochemistry, Molecular Diagnostics, Philipps University Marburg, University Hospital Gießen and Marburg GmbH, Marburg, Deutschland

${ }^{2}$ Institut für Medizinische Diagnostik $\mathrm{GmbH}$, Immunologie, Bioscientia, Ingelheim, Deutschland

Synonym(e) LPS-Rezeptor

Englischer Begriff LPS receptor; LPS-R

Definition Lipopolysaccharid(LPS)-Rezeptor.

\section{Molmasse ca. $48 \mathrm{kDa}$.}

Funktion - Pathophysiologie Der Komplex aus löslichem CD14 und LPS kann Zellen stimulieren, die anders als - Monozyten/ $\triangleright$ Makrophagen kein membrangebundenes CD14 exprimieren (z. B. Endothelzellen und einige Arten epithelialer Zellen). Die Stimulation führt zu vermehrter Freisetzung von Zytokinen und Adhäsionsmolekülen.

\section{Literatur}

www.ncbi.nlm.nih.gov 